\title{
Sistem Monitoring Tinggi Permukaan Air Panci Penguapan Berbasis Node MCU Dengan Menggunakan Teknologi Internet of Things (IoT)
}

\author{
Ilham Darwin Gani, \\ Program Studi Teknik Elektro \\ Fakultas Teknik \\ Universitas Khairun \\ Ternate, Indonesia \\ email: ilham.gani24@gmail.com,
}

\author{
Mohamad Jamil, \\ Program Studi Teknik Informatika \\ Fakultas Teknik \\ Universitas Khairun \\ Ternate, Indonesia \\ jamilkhairun@gmail.com
}

\author{
Achmad P. Sardju \\ Program Studi Teknik Elektro \\ Fakultas Teknik \\ Universitas Khairun \\ Ternate, Indonesia \\ mattsardju@gmail.com
}

\begin{abstract}
Abstrak - Panci penguapan kelas A digunakan di semua BMKG di Indonesia sebagai alat ukur penguapan. cara pengukuran ketinggian permukaan air panci untuk mendapatkan nilai penguapan masih manual. Dengan adanya perancangan sistem monitoring ini diharapkan bisa membantu memonitoring ketinggian air panci penguapan secara otomatis. Perancangan sistem monitoring tinggi muka air ini menggunakan Node MCU ESP8266 sebagai mikrokontroler yang sudah dilengkapi dengan fitur wifi dan firmwarenya yang bersifat open source, konsep sistem monitoring tinggi permukaan air ini menggunakan sensor jarak dengan output LCD dan juga ditampilkan pada komputer pemantau sebagai penampil nilai-nilai ketinggian air yang telah diprogramkan dalam tampilan web dengan menggunakan teknologi Internet Of Things (IoT). Sistem yang dirancang ini bekerja dengan output tegangan $12 \mathrm{~V}$ dan 5V. untuk tegangan pada LCD I2C dan sensor ultrasonok menggunakan $12 \mathrm{~V}$, sedangkan $5 \mathrm{~V}$ untuk node MCU. Pengujian ini dilakukan selama 7 hari, sampel data pengukuran dikirim ke Thingspeak minimal setiap 25 detik tergantung koneksi jaringan wifi. Data yang telah diambil terjadi perubahan ketinggian air dari $13 \mathrm{~cm}$ ke $14 \mathrm{~cm}$ terjadi setelah 27 jam, kemudian perubahan ketinggian air dari $14 \mathrm{~cm}$ ke $15 \mathrm{~cm}$ terjadi setelah 26 jam.
\end{abstract}

Kata kunci : Sistem Monitoring; Internet of Things (IoT); ThingSpeak; Node MCU ESP8266; Sensor Ultrasonik HCSR04.

\section{PENDAHULUAN}

Penguapan merupakan unsur yang sangat penting dalam proses hidrologi, akan tetapi tidak semua analisis dalam hidrologi menggunakan variabel penguapan sebagai bagian yang penting. Evaporasi adalah penguapan dari permukaan air, tanah, dan bentuk permukaan, bukan vegetasi oleh proses fisika. Dua unsur utama untuk berlangsungnya evaporasi adalah energi (radiasi) matahari dan ketersediaan air. Sebagian radiasi gelombang pendek (shortwave radiation) matahari akan diubah menjadi energi panas di dalam tanaman, air, dan tanah. Panas yang dipakai untuk menghangatkan partikel-partikel di udara dan tanpa mengubah bentuk partikel tersebut dinamakan panas tampak (sensible heat). Sebagian dari energi matahari akan diubah menjadi tenaga mekanik, tenaga mekanik ini akan menyebabkan perputaran udara dan uap air. Ketersediaan air yang dimaksud melibatkan tidak saja jumlah air yang ada, tapi juga persediaan air yang siap untuk terjadinya evaporasi.

Stasiun meteorologi kelas I Babullah Ternate menggunakan panci penguapan kelas A sebagai alat ukur penguapan. Panci penguapan kelas A juga digunakan di semua BMKG di Indonesia, tentu terdapat beberapa alasan digunakannya panci penguapan kelas A sebagai alat ukur penguapan, untuk itu penelitian ini mencoba menganalisis pengukuran penguapan dari sisi prinsip kerjanya. Peristiwa air atau es menjadi uap dan naik ke udara disebut penguapan dan berlangsung tidak berhenti dari permukaan air, permukaan tanah, padang rumput, persawahan, hutan dan lain-lain. Pada satasiun meteorologi kelas I Babullah Ternate cara yang dilakukan untuk mengukur besar pengupan masih manual, maka dengan penelitian yang dilakukan agar bisa membantu memonitoring besar penguapan dengan cara yang otomatis.

Perancangan sistem monitoring tinggi muka air ini dengan menggunakan Node MCU ESP8266 sebagai mikrokontroler, dimana kaki dari pin Node MCU ini dihubungkan dengan komponen-komponen lain seperti sensor ultrasonik HC-SR04, LCD I2C, catu daya. Konsep sistem monitoring tinggi permukaan air dengan menggunakan sensor jarak dengan output LCD dan ditampilkan pada komputer pemantau sebagai penampil nilainilai ketinggian air yang telah diprogramkan dalam tampilan web dengan menggunakan teknologi Internet Of Things (IoT). 
Terdapat beberapa perancangan sistem monitoring yang dikembangkan sebelumnya, perancangan yang berfokus pada penerapan yang berbeda-beda, melalui berbagai metode yang digunakan. Pada penelitian (Fikri et al. 2015) sistem monitoring ketinggian permukaan air menggunakan mikrokontroler ATmega328P berbasis web service. Data dari hasil pengukuran yang dikirim dari mikrokontroler ke web server melalui koneksi internet, agar data hasil pengukuran nantinya dapat terikirim ke database maka diperlukan modul ethernet untuk menghubungkan sistem ke jaringan internet. Modul ethernet yang digunakan ialah modul ethernet ENC28J60, kita sebagai pengguna dapat mengakses data hasil pengukuran melalui halaman web.

(Tricahyo, Sandy, and Satrio 2017). membuat alat pendeteksi banjir untuk proteksi rumah ketika banjir terjadi yang bertujuan untuk mengimplementasikan dan mengadopsi sistem proteksi dini agar tidak terjadi korsletting listrik saat terjadi banjir, alat ini juga dapat membaca percepatan air sehingga akan bisa di baca kondisinya apakah berpotensi banjir atau tidak untuk pemantauan realtime. Alat tersebut dikembangkan dengan sistem Internet Of Things (IoT) yang komunikasinya dilakukan secara wireless dengan media mikrokontroller ESP8266 dan sensor ultrasonik untuk mendeteksi ketinggian air dan percepatan air berbasis web.

Perancangan konsep sistem monitoring tinggi muka air ini dengan menggunakan Node MCU ESP8266, dimana kaki pin dari Node MCU ESP8266 ini dihubungkan dengan komponen-komponen lain seperti sensor SRF04, LCD I2C, catu daya. Konsep sistem monitoring tinggi permukaan air dengan menggunakan sensor jarak dengan output LCD dan ditampilkan pada komputer pemantau sebagai penampil nilainilai ketinggian air yang telah diprogramkan dalam tampilan web dengan menggunakan teknologi Internet of Things (IoT).

Sistem yang dirancang ini beroperasi menggunakan program yang disimpan didalam Node MCU ESP8266 sebagai mikrokontroler, oleh karena itu dibutuhkan konsep yang baik agar mendapatkan hasil yang sesuai tujuan. Untuk mendapatkan hasil yang maksimal dalam penilitian ini, maka yang perlu dilakukan adalah bagaimana desain sistem sensor ketinggian level air yang sesuai untuk pengukuran dan bagaimana cara untuk mendapatkan nilai-nilai ketinggian air kedalam Node MCU dengan chip ESP8266 yang dapat mengirim data ketinggian air secara otomatis pada komputer, dengan beberapa komponen pelengkap yang ditambahakan agar hasil pemantauan dapat berjalan dengan baik dan data yang dihasilkan lebih akurat.

\section{METODOLOGI PENELITIAN}

\section{Flowchart Proses Perancangan dan Pembuatan Alat}

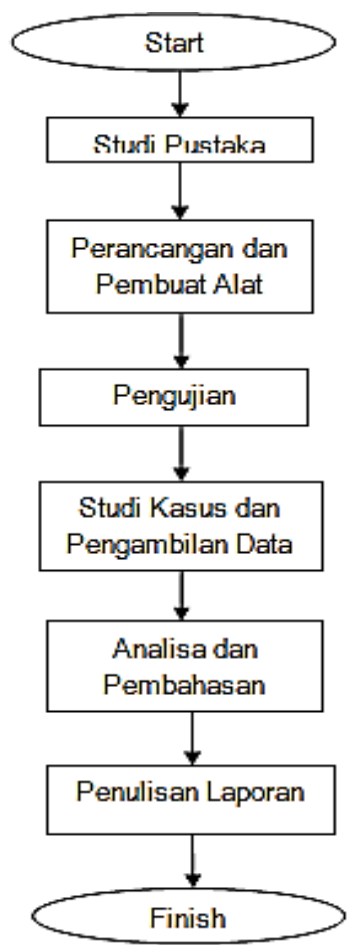

Gambar 1. Flowchart Proses Perancangan dan Pembuatan Alat

Flowchart proses perancangan dan pembuatan alat, dimana sebelum merancang dan membuat prototype sistem monitoring ini dilakukan studi pustaka terlebih dahulu yang bertujuan untuk mendapatkan referensi-referensi mengenai sistem monitoring. Setelah dilakukannya studi pustaka dilanjutkan dengan proses perancangan dan pembuatan modul sistem monitoring tinggi muka air, selanjutnya sistem tersebut di uji, kemudian dilanjutkan dengan studi kasus dan pengambilan data pada tempat yang ditentukan, dan hasil dari pengambilan data dan studi kasus disusun pada tahap terakhir yaitu penyususnan laporan akhir.

\section{Diagram Blok Perancangan Sistem}

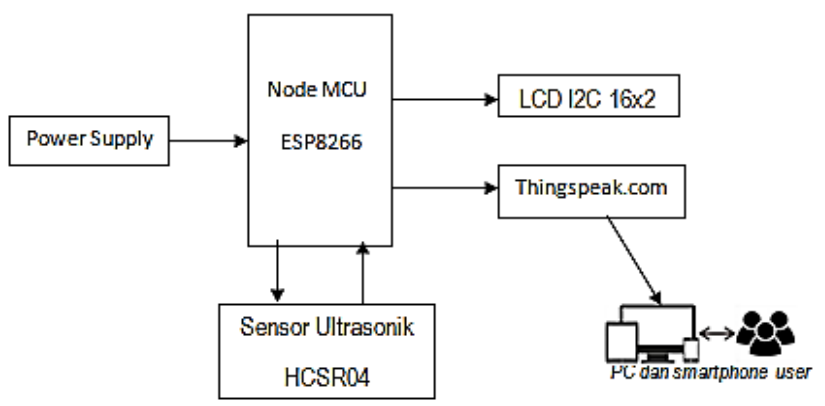

Gambar 2. Diagram Blok Perancangan Sistem Monitoring Tinggi Muka Air

1. Sensor ultrasonic distance sensor, dipilih karena sudah dilengkapi dan dikemas dengan baik sehingga dapat mengurangi interferensi sinyal yang dipancarkan dan diterima. Modul ini dipasang menghadap permukaan air sehingga dapat mengukur jarak muka air ke receiver. 
2. Node MCU merupakan perangkat keras/platform Internet Of Things (IoT) yang open source seperti arduino. Platform ini termasuk firmware yang berjalan pada ESP8266 Wi-Fi SoC dari Espressif System, dan pada perangkat keras yang berbasis modul ESP-12 atau chip ESP8266-12E. Node MCU pada dasarnya adalah pengembangan dari ESP8266 dengan firmware berbasis e-Lua. Pada penelitian ini digunakan Node MCU sebagai system pengendali dari perangkat keras. Hasil dari pengukuran sensor tinggi muka air dikirim oleh Node MCU ke web server (Thingspeak) secara otomatis dengan bantuan jaringan internet.

3. LCD digunakan sebagai media pemantauan data jarak tinggi muka air yang terhubung langsung dengan sistem monitoring tinggi muka air, dan sebagai perbandingan dari data yang diterima web server.

4. Power suplay digunakan dalam sistem ini karena merupakan suatu rangkaian penyearah yang dilengkapi dengan beberapa komponen yang dirangkai dalam suatu sistem yang disebut power suply.

5. Komputer/PC atau smartphone digunakan sebagai media untuk melihat maupun mengambil data yang diterima langsung dari web server Thingspeack.

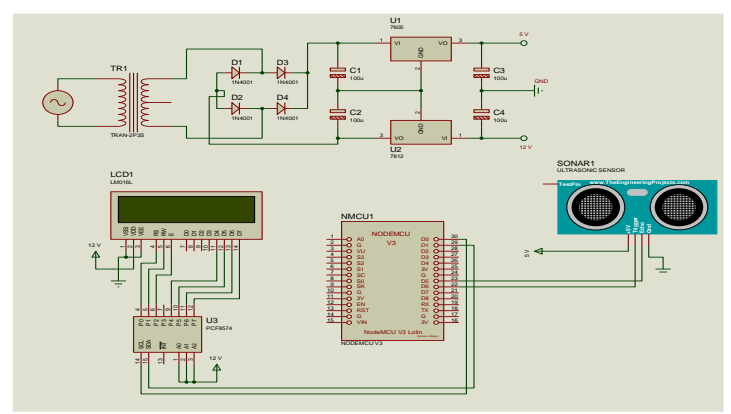

Gambar 3. Rangkaian Keseluruhan Sistem Monitoring Tinggi Muka Air

Komponen - komponen dan cara kerja dari rangkaian keseluruhan sistem monitoring tinggi muka air di atas adalah sistem ini akan bekerja dengan dua output tegangan yang dikeluarkan catu daya yaitu $12 \mathrm{~V}$ dan $5 \mathrm{~V}$, output $12 \mathrm{~V}$ untuk menyuplai tegangan pada LCD I2C dan sensor ultrasonik, sedangkan output $5 \mathrm{~V}$ untuk menyuplai tegangan khusus untuk node MCU melalui port micro USB pada node MCU sebagai mikrokontroler atau otak dari sistem ini dan pin-pin output dari node MCU akan di konfigurasi pada pin dari LCD dan sensor.

Pin yang digunakan untuk konfigurasi node MCU dengan sensor adalah pin output D5 node MCU dengan pin Echo pada sensor yang berfungsi untuk mendeteksi sinyal pantulan ultrasonik, pin D6 node MCU dengan pin trigger pada sensor yang berfungsi untuk membangkitkan sinyal ultrasonik. Dan untuk konfigurasi node MCU dengan modul I2C pada LCD pin yang digunakan adalah D1 node MCU dengan pin SCL pada modul I2C LCD yang berfungsi mengirim informasi data, pin D2 node MCU dengan pin SDA pada modul I2C LCD berfungsi menerima informasi data.

\section{HASIL DAN PEMBAHASAN}

Hasil pengujian sistem perancangan keseluruhan

Pengujian sistem perancangan ini merupakan pengujian yang dilakukan untuk dapat memperoleh data hasil jarak ketinggian permukaan air dan penguapan air. Data dari hasil pengukuran sistem akan ditampilkan atau dimonitoring dan diarsipkan secara online, maupun dapat dimonitoring secara langsung berupa teks di LCD 16x2 yang terdapat pada alat sistem monitoring. Sedangkan yang online dapat dimonitoring secara visual berupa grafik dan diarsipkan di cloud database thingspeak dengan tipe file .csv.

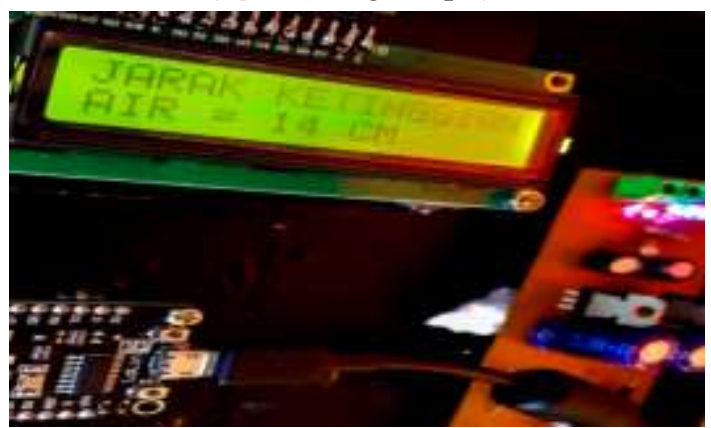

Gambar 4. Monitoring Langsung Dengan LCD 16x2

Monitoring secara langsung pada LCD, jika ingin mengetahui data ketinggian air maka bisa langsung saja ke alat sistem monitoring dan data yang ditampilkan berupa teks pada LCD 16x2. Sedangkan untuk monitoring online dan pengarsipan online dapat dilihat pada gambar di bawah ini:

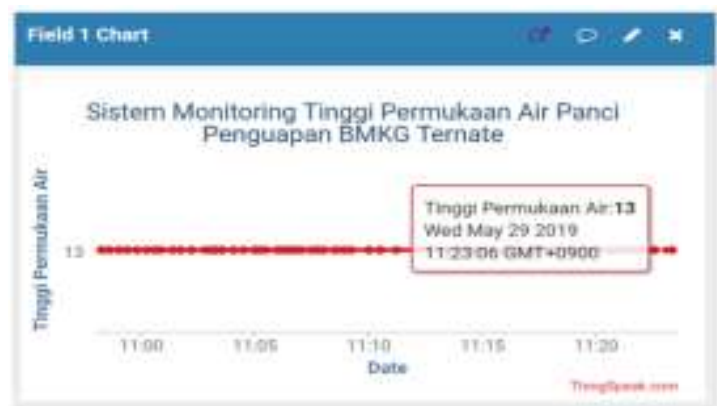

Gambar 5. Grafik Hasil Pengukuran Tinggi Permukaan Air Hari Pertama

Tinggi permukaan air pada hari pertama pengukuran belum terjadi perubahan pada grafik karena untuk mengetahui adanya penguapan pada air hingga perubahan ketinggian permukaan air harus melalui proses 24 jam dan suhunya harus terpapar langsung dibawah terik sinar matahari.

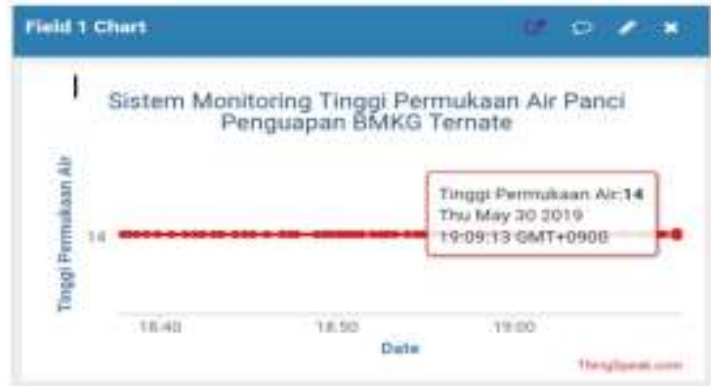

Gambar 6 Grafik Hasil Pengukuran Tinggi Permukaan Air Hari kedua 
Tinggi permukaan air pada hari kedua pengukuran, sudah terlihat perubahan nilai tinggi permukaan air yang terjadi pada grafik gambar 6 karena dalam proses penguapan pada hari pertama panas matahari yang dipancarkan sangat terik sehingga suhu pada air juga panas maka terjadilah penguapan.

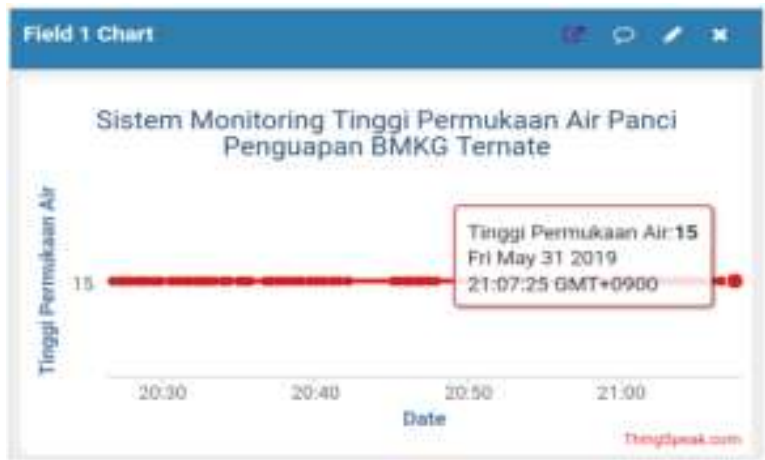

Gambar 7. Grafik Hasil Pengukuran Tinggi Permukaan Air Hari ketiga

Tinggi permukaan air pada hari ketiga pengukuran, juga terlihat perubahan nilai tinggi permukaan air yang terjadi pada grafik gambar 7 karena dalam proses penguapan pada hari kedua panas matahari yang dipancarkan juga sangat terik sehingga suhu pada air juga panas dan terjadilah penguapan.

Nilai yang ditampilkan pada grafik adalah jarak antara sensor dan permukaan air, maka jika airnya menurun maka pembacaan nilai sensor naik. Namun nilai sensor akan berubah - ubah atau tidak stabil bila air bergelombang yang disebabkan oleh angin kencang. Seperti yang terjadi pada grafik gambar 8 di bawah ini.

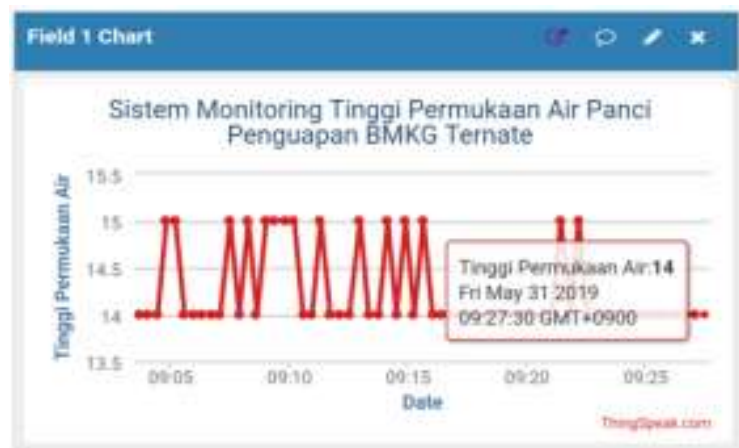

Gambar 8. Grafik Hasil Pengukuran Tinggi Permukaan Air Perancangan Sistem yang bergelombang

Hasil monitoring dengan tampilan beberapa grafik di atas adalah hasil monitoring secara online, maka untuk pengarsipannya berada pada cloud database yang siap di download pada jendela Data Import/Export, seperti pada gambar 9 di bawah ini

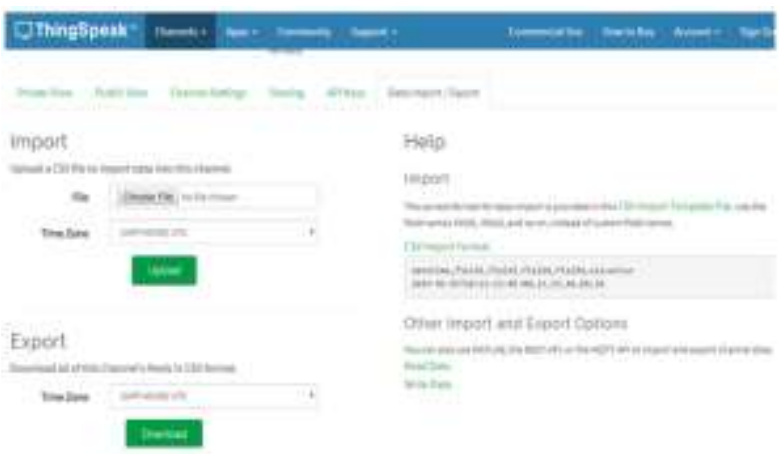

Gambar 9. Window Download Data pada Cloud Database thingspeak.com

Data yang didownload berupa file .csv dengan nama file feeds.csv. filenya dapat dilihat digambar berikut ini:

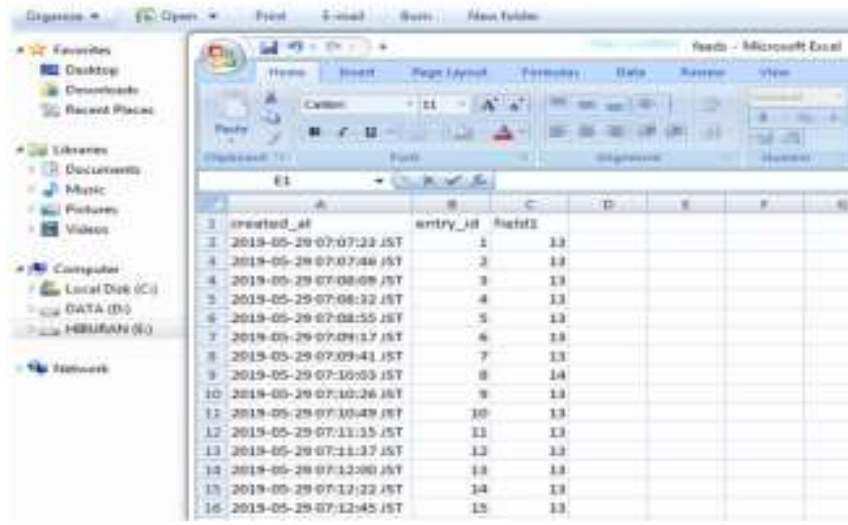

Gambar 10. Data Hasil Download dari Cloud Database Thingspeak.com

Dilihat dari gambar 5 sampai dengan gambar 10 diatas merupakan data dari hasil pengukuran sistem monitoring dan pengarsipan secara online. Data yang dikirim secara otomatis ditampilkan dan diarsipkan di cloud database thingspeak.com.

Dari pengambilan data selama 7 hari data yang diarsipkan adalah sebanyak 18179 data. Lamanya pengiriman data tergantung dengan koneksi internet, akan tetapi sesuai dengan pengaturan program yang ditulis.

Pengukuran tinggi muka air panci penguapan bertujuan untuk mengetahui seberapa besar air yang terjadi penguapan pada panci penguapan stasiun BMKG kelas I Babullah Ternate. Tapi pengambilan data pada penelitian ini menggunakan cerek ukur sebagai wadah air untuk pengukuran selama 7 hari, dikarenakan situasi dan kondisi di lapangan tempat panci penguapan stasiun BMKG kelas I Babullah Ternate tidak memungkinkan untuk pengambilan data selama 24 jam dalam 7 hari. Posisi sensor jarak yang berada di permukaan cerek ukur yang ditampung air, dan posisi cerek ukur tersebut diletakan di tempat yang tak tarhalang oleh bangunan dan pohon supaya bisa langsung terkena paparan sinar matahari. 


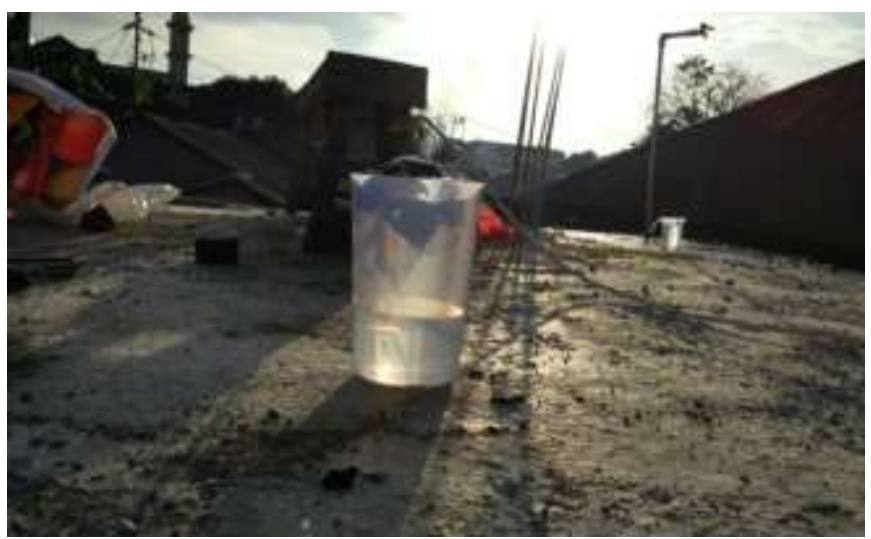

Gambar 11. Posisi Sensor Ultrasonik Yang Berada di Permukaan Cerek Ukur

Data hasil pengukuran ketinggian air ini diambil selama 24 jam dalam 7 hari dan sistem secara otomatis menyimpan data di cloud database thingspeak.com. Pengambilan data pada hari pertama dimulai pada pukul 07:07:23 dan berlangsung selama 7 hari dan pada hari terakhir pengambilan data hanya berlangsung sampai pukul 17:31:21.

\section{KESIMPULAN}

Dari proses perancangan hingga pengujian dan hasil yang didapatkan, dapat ditarik kesimpulan bahwa sistem ini bekerja dengan output tegangan $12 \mathrm{~V}$ dan $5 \mathrm{~V}$. Untuk tegangan pada LCD I2C dan sensor ultrasonik menggunakan $12 \mathrm{~V}$, sedangkan 5V untuk untuk node MCU. Komudian pin Echo dan Trigger dari sensor ultrasonik dikonfigrasikan dengan pin D5 dan D6 pada node MCU, dan pin D1, D2 dari node MCU konfigurasikan dengan pin SCL, SDA pada LCD I2C. Pengujian dilakukan selama 7 hari, sampel data pengukuran dikirim ke Thingspeak minimal setiap 25 detik tergantung koneksi jaringan wifi. Data yang telah diambil terjadi perubahan ketinggian air dari $13 \mathrm{~cm}$ ke $14 \mathrm{~cm}$ terjadi setelah 27 jam, kemudian perubahan ketinggian air dari $14 \mathrm{~cm}$ ke 15 cm terjadi setelah 26 jam

\section{DAFTAR PUSTAKA}

[1] Rausan Fikri, Boni P. Lapanporo, dan Muh Ishak Jumarang. (2015). Rancang Bangun Sistem Monitoring Ketinggian Permukaan Air Menggunakan Mikrokontroler ATMEGA328P Berbasis Web Service.

[2] Mokh. Sholihul Hadi, Danang Alfian Tricahyo, Dimas Kurniawan Sandy, Fauzy Satrio Wibowo. (2017). IOT cloud data logger untuk sistem pendeteksi dini bencana banjir pada pemukiman penduduk terintegrasi media sosial.

[3] Jati, E. W. \& Arrofiq M. (2013). Sistem pemantau ketinggian air sungai dengan tampilan pada situs jejaring sosial twitter sebagai peringatan dini terhadap banjir, 7984.

[4] Sayekti, A. N. R., (2013). Perancangan sistem monitoring tinggi muka air berbasis mikrokontroler pada daerah aliran sungai.

[5] Ahmad Khamdi Musthofa (2014). Sistem monitoring ketinggian air sungai menggunakan sensor ultrasonik berbasis mikrokontroler 8535 .

[6] A. Wiedjaja, M. Handy, l. Jonathan, I. I. Ahmad, and j. A. H. Simatupang, (2012). Pemantauan tinggi air otomatis untuk bendungan katulampa melalui via sms.

[7] Riny Sulistyowati, Hari Agus Sujono, dan Ahmad Khamdi Musthofa (2015) Sistem Pendeteksi Banjir Berbasis Sensor Ultrasonik Dan Mikrokontroler Dengan Media Komunikasi Sms Gate Way.

[8] Achmad Muzakky, Akhmad Nurhadi, Ashuri Nurdiansyah, Galih Wicaksana, Istiadi (2018) Perancangan Sistem Deteksi Banjir Berbasis IOT

[9] Indrianto, Ferry Sudarto, Siti Juhriah Novianty (2018) Pengontrolan Ketinggian Air Pada Bak Penampung Berbasis Node MCU

[10]Erick Sorongan, Qory Hidayati, Kuat Priyono (2018) ThingSpeak sebagai Sistem Monitoring Tangki SPBU Berbasis Internet of Things

[11]Eljire Bagas Lewi, Unang Sunarya, S.T., M.T, Dadan Nur Ramadan, S.Pd., M.T (2016) Sistem Monitoring Ketinggian Air Berbasis Internet Of Things Menggunakan Google Firebase Water Level Monitoring System Based On Internet Of Things Using Google Firebase

[12] Alawiah, AmeliaRafi Al Tahtawi, Adnan (2018) Sistem Kendali dan Pemantauan Ketinggian Air pada Tangki Berbasis Sensor Ultrasonik

[13] Ulumuddin, USudrajat, MRachmildha, T DIsmail, NHamidi, E A Z (2017) Prototipe Sistem Monitoring Air Pada Tangki Berbasis Internet of Things Menggunakan Nodemcu Esp8266 Sensor dan Ultrasonik

[14]Heru Susanto, Agus Nurcahyo (2018) Desain Dan Implementasi Sistem Monitoring Tegangan Dan Arus Motor Induksi Tiga Phase Menggunakan Konsep Internet Of Things (IOT)

[15[Samuel Siregar dan Muhammad Rivai (2019) Monitoring dan Kontrol Sistem Penyemprotan Air Untuk Budidaya Aeroponik Menggunakan NodeMCU ESP8266 